\title{
CONSIDERAÇÕES SOBRE O CONCEITO DE TEATRALIDADE
}

\author{
Prof. dr. Edelcio Mostaço ${ }^{1}$
}

Palavras-chave: teatro brasileiro, teatro jesuítico, Missões, teatralidade.

Resumo: o presente texto aborda a questão da teatralidade, importante conceito aqui aprofundado como opção metodológica para subsidiar a pesquisa em curso. Percorre as noções de mimetismo, jogo e representação na antropologia, na sociologia e na história, procurando destacar vínculos aproveitáveis para a percepção e a análise estética.

A noção de teatralidade é complexa, a despeito de sua aparente simplicidade em constituir-se como um substantivo urdido a partir do adjetivo teatral. Em sua acepção comum e mais divulgada, a teatralidade designa algo levemente ostentatório ou arbitrariamente empreendido para gerar um efeito. Uma sala de estar que desperte tal menção significa que aparenta ser cenográfica; assim como, tratando-se de uma pessoa, se afetar um comportamento algo exagerado, solene ou demasiadamente polido e cortês. Constantin Stanislávski usava o termo para designar atores caricaturais, falsos, empolados ou cujas expressividades soassem distante do verdadeiro ou do natural, evidenciando possuir por padrão artístico de referencia o verossímil - o que inclinava sua acepção de teatralidade como depreciadora. Vsevoldod Meyerhold, ao propugnar o teatro teatral por ele forjado, insistia em destacar na cena exatamente sua característica construída, artística, resultado de signos inflados de significação que poderiam, facilmente, ser tomados como símbolos. A teatralidade, nessa acepção, surge valorada positivamente, como uma virtude artística.

Recorrer à evolução desse conceito pode ajudar a compreensão, em maior escala, da oscilação dos significados que conheceu e acumulou. Querendo exprimir "conformidade de uma obra dramática às exigências fundamentais da construção teatral", o dicionário francês Petit Robert registra o termo a partir de 1842; deixando claro o tipo de consciência dos teóricos daquele momento em relação ao que fosse o teatro. Ou seja, como herança legada desde a Renascença, era o texto o elemento definidor mais proeminente para designar o fenômeno teatral. Essa crença foi alcunhada de textocentrismo, por depositar nas palavras ou no espírito do autor não apenas o reconhecimento da autoria, como, com ênfase maior, que era ele o verdadeiro e único agente criativo ou criador no âmbito cênico.

Retroativamente, o rasto dessa sacralidade impregnando o texto teatral leva-nos a perceber suas iniciais manifestações junto aos doctes e connaisseux, grupos organizados em cabalas no coração do século XVII, agindo para valorizar os autores de tragédias e comédias em detrimento das demais manifestações cênicas adjacentes, como a comédiabalé, a farsa, os divertimentos, as mascaradas e, sobretudo, a commedia dell'arte, todas consideradas traquinagens eivadas de uma espontaneidade que, rebeldes às

\footnotetext{
${ }^{1}$ Orientador do projeto "O TEATRO DAS MISSÕES - uma nova perspectiva histórica sobre o teatro no Brasil Colônia", Professor do Depto. de Teatro e Programa de Pós-Graduação em Teatro, situado à Av. Madre Benvenuta, 1907, cep 88035-001, Florianópolis, SC, fone: 3321-8353, e.mail: c2emo@udesc.br
} 
classificações, encontravam-se fora do alcance da Academia de Arte. O autor teatral, desde então, passou não apenas a ser reconhecido e aplaudido como, e talvez seja esse o aspecto crucial da questão, remunerado. Escrevendo sob contrato, fornecendo originais a essa ou aquela companhia, difundia e responsabilizava-se por um selo de qualidade que, com o tempo, conferiu um perfil distintivo às diferentes casas de espetáculos, sedimentando um sem número de convenções que, aos poucos, tenderam a se cristalizar. $^{2}$

Tal é, portanto, o tipo de "conformidade à arte teatral" requerida pela teoria teatral na época do Petit Robert. O lento desenvolvimento da encenação, na segunda metade do século, foi impondo, paulatinamente, novos horizontes à consideração dos teóricos e do público, fazendo retornar o espírito do autor para junto de seus restos mortais. Quem poderia zelar pelo espírito de Shakespeare, de Racine, de Voltaire - senão os críticos positivistas, os mais ferrenhos detratores da nascente encenação? Fortemente vinculada ao naturalismo, através de André Antoine, a encenação surgiu para contrapor-se a diversos exageros presentes nos palcos do período, como os monstros-sagrados, os cenógrafos de gabinete e os gêneros ligeiros que acaçapavam o gosto das platéias com seus rompantes de exibicionismo e excentricidades.

\section{Arte e vida}

Refazer a trilha percorrida pela noção de teatralidade implica em dimensioná-la nos distintos contextos onde foi empregada. Em 1908 o dramaturgo e encenador russo Nicolai Evreinov (1879-1953) postulava, em sua obra Apologia da Teatralidade, a existência de um instinto teatral inerente aos animais superiores, querendo designar a capacidade mimética de jogo que manifestam. O ser humano, nessa acepção, seria o mais apto a desenvolvê-la em modo reflexivo, tomando tal princípio como uma das dimensões mais acalentadas pela espécie humana:

\footnotetext{
"o homem possui um instinto inesgotável de vitalidade, sobre o qual nem os historiadores, nem os psicólogos, nem os estetas jamais disseram a menor palavra até agora. Refiro-me ao instinto de transfiguração, o instinto de opor as imagens recebidas de fora, as imagens arbitrariamente criadas de dentro; o instinto de transmudar as aparências oferecidas pela natureza em algo distinto. Em resumo, um instinto cuja essência se revela no que eu chamaria de 'teatralidade'. ${ }^{3}$
}

Prossegue o autor, destacando as características inatas desse impulso que se encontra na base de todas as transfigurações experimentadas pelo ser humano, em todas as épocas. "A teatralidade é pré-estética, ou seja, primitiva e de caráter mais fundamental que nosso sentido estético. (...) Quando um selvagem fura o nariz e nele

\footnotetext{
${ }^{2}$ Para desdobramentos ver, entre outros, SCHERER, J. La dramaturgie classique en France. Paris. Nizet, s/d.; LAGRAVE, H. Le théàtre et le public à Paris de 1715 à 1750. Paris. Bordas: 1972; THOORENS, Leon. Le dossier Molière. Verviers. Gerard \& Co.: 1964; LARTHOMAS, Pierre. Le langage dramatique. Paris. Puf: 1972; ROUBINE, Jean-Jacques. A linguagem da encenação teatral. Rio de Janeiro. Zahar: 1982; CHARTIER, Roger. Do palco à página. Rio de Janeiro. Casa da Palavra: 2002.

${ }^{3}$ No Ocidente, esse texto integra uma coletânea de seus escritos: EVREINOV, Nicolai. El teatro y la vida. Buenos Aires. Leviatã: s/d, p. 35. Em 1909 Evreinov lançou A teoria do monodrama, um novo enfoque para a construção dramatúrgica, fundamentalmente alicerçada sobre a auto-imagem e a narratividade, que passou quase despercebido em sua época. Pensador impregnado pelo simbolismo então vigente, sua grande tese pode ser assim resumida: "voltar a teatralizar o teatro para teatralizar consciente e intensamente a vida".
} 
introduz um osso de baleia não o faz com o propósito de espantar seus inimigos ou para produzir maior efeito na guerra, senão pela pura alegria da auto-transfiguração." ${ }^{4}$

Ao longo da década de 1930, quase simultâneos e, aparentemente, sem conhecer as pesquisas um do outro, dois estudiosos enveredaram pelo território do jogo e suas funções culturais. O primeiro é o antropólogo Marcel Jousse, discípulo de Bergson, Levy-Bruhl e Marcel Mauss, orientado para a compreensão do universo pré-lógico da mente humana a partir dos fenômenos culturais. Para ele o mimetismo ocupa um papel fundamental junto a toda e qualquer pedagogia, poderosa força de construção quanto à imersão da criança na esfera cultural, desde a fala até os gestos. Assim, aquilo que vemos e não podemos deixar de ver, aquilo que ouvimos e não podemos deixar de ouvir, não se detêm em nosso ouvido ou nosso olho, mas irradia-se por todo nosso corpo, no composto humano que somos. Nosso corpo é, pois, uma espécie de argila biológica onde se imprime o universo que nos rodeia e que imediatamente absorvemos e exprimimos, em modo reflexivo.

Razão pela qual o jogo ocupa papel central nessas considerações, pois o pensamento supõe a introjeção (intussuscepcion) da realidade, assim como sua reprodução mediante o uso de todo o corpo, como fazem espontaneamente as crianças quando jogam, pois o corpo é inteligente e exprime pensamentos: "não é o gesto que sublinha o pensamento, mas sim o gesto que suscita o pensamento", afirma ele. ${ }^{5} \mathrm{~A}$ interação com o universo que o rodeia, a aprendizagem da língua, da leitura, do desenho, da escritura, bem como o desenvolvimento cerebral bifásico e trifásico constituem, para Jausse, desdobramentos dessa capacidade mimética inerente ao ser humano, princípios que a educadora Maria Montessori irá explorar e empregar ulteriormente.

O segundo pesquisador do jogo é Johan Huizinga. Em sua muito divulgada obra Homo Ludens afirma: "é no mito e no culto que têm origens as grandes forças instintivas da vida civilizada: o direito e a ordem, o comércio e o lucro, a indústria e a arte, a poesia, a sabedoria e a ciência. Todas elas têm suas raízes no solo primeiro do jogo." 6

Ao contrário do "instinto" preconizado por Evreinov e do mimetismo co-genial defendido por Jausse, o jogo é, para o pensador flamengo, uma atividade livre, arbitrária, podendo a qualquer hora e tempo ser suspenso ou interrompido no confronto com o real: "trata-se de uma evasão da vida real para uma atmosfera de atividade com orientação própria. Toda criança sabe perfeitamente quando está 'fazendo de conta' ou quando está 'só brincando", conclui Huizinga. ${ }^{7}$

Uma interação mais complexa dessas noções ligadas ao mimetismo e ao jogo será encontrada nas teorias de D.W. Winnicott, psicólogo inglês criador da chamada psicologia transacional. Pra ele o bebê, desde os primeiros dias de vida, passa a delimitar o que é (seu próprio corpo) e o que não-é (o mundo exterior), criando relações ou transações. Esse processo complexo implica várias fases ou estados anímicos desenvolvidos pelo infante, indo de sua capacidade de reconhecer objetos como "nãoeu" até procurar e localizar objetos e pessoas que se encontram fora dele, dentro ou na zona de fronteira entro o dentro e o fora. Esse processo estrutura-se através de jogos sucessivos e incrementa a capacidade do infante em criar, imaginar, inventar, originar ou produzir tais objetos transacionais, entendendo-se aqui por objetos também as pessoas e o mundo que o rodeiam. "Introduzi os termos 'objetos transacionais' e

${ }^{4}$ Idem, ibidem, pg. 37.

${ }^{5}$ JAUSSE, Marcel. “ A evolução pedagógica da criança, laboratório de ritmo-pedagogia 1933-1934”, in

L'anthropologie du geste. Paris. Resma: 1969, p. 37.

${ }^{6}$ HUIZINGA, Johan. Homo Ludens. São Paulo. Perspectiva: 1971, p. 7.

${ }^{7}$ Idem, ibidem, p. 11. 
'fenômenos transacionais' para designar a área intermediária da experiência, entre o polegar e o ursinho, entre o erotismo oral e a verdadeira relação de objeto, entre a atividade criativa primária e a projeção do que já foi introjetado, entre $o$ desconhecimento primário de dívida e o reconhecimento desta (Diga: "bigado")", conclui ele em sua obra $O$ Brincar e a Realidade. ${ }^{8}$

Desde a mais tenra infância, portanto, o ser humano está às voltas com os fenômenos concernentes à representação, de si mesmo e do mundo, articulando diferentes modos de mimetizar o real e com ele interagir.

O sociólogo Erving Goffman tornou célebre seu estudo dedicado ao desempenho dos papéis sociais, as funções representacionais que as sociedades complexas engendram, sob a rubrica de "teoria do personagem". Seu enfoque recaiu, especialmente, sobre o sutil e indispensável sentido de representação que perpassa os desempenhos profissionais: o médico, o engenheiro, o vendedor, entre outros, necessitam transmitir confiança e credibilidade aos clientes e consumidores, sob pena de não sobreviverem em suas áreas de atuação. Tais representações na vida cotidiana dão corpo à teatralidade e à dramatização inerentes à própria vida social, uma nova dimensão da auto-apresentação dos indivíduos entre si, atando fortemente os laços da interatividade.

Após destacar o papel e a função fundamentais de jogo perpassando essas práticas da interação social e as relações inter-subjetivas que desencadeiam, Goffman conclui:

\begin{abstract}
"as perspectivas política e dramatúrgica entrecuzam-se claramente no que diz respeito à capacidade que um indivíduo tem de dirigir a atividade de outro. Em primeiro lugar, se um indivíduo tem de dirigir outros, muitas vezes julgará útil guardar deles segredos estratégicos. Além disso, se um indivíduo tenta dirigir a atividade de outros por meio de exemplos, do esclarecimento, persuasão, intercâmbio, manipulação, autoridade, ameaça, punição ou coerção, será necessário, qualquer que seja sua posição de poder, transmitir eficazmente o que deseja que se faça, o que está preparado para conseguir que seja feito e o que fará, caso isso não seja cumprido. Qualquer tipo de poder deve estar revestido de meios eficientes que o exibam, e terá diferentes efeitos, dependendo do modo como é dramatizado." 9
\end{abstract}

Num emblemático conjunto de ensaios denominado $O$ mundo como teatro ${ }^{10}$, Peter Burke reconheceu a importância dos assentamentos de Goffman, preconizados, como se sabe, por Thorstein Veblen e sua A teoria da classe ociosa. Para encetar esse finíssimo diagnóstico sobre o comportamento das elites, onde o "consumo ostentatório" surge como um traço quer de distinção quer de emulação social, Veblen valeu-se das anotações realizadas por Franz Boas em seu estudo sobre os Kwakiutl, tribo habitante da região de Vancouver nas primeiras décadas do século XIX. Cultivavam eles um modo de potlach, através do qual, ao se desfazerem de certos objetos considerados símbolos de riqueza, desafiavam os rivais a também se desfazerem dos seus, um modo assaz curioso de ostentar riqueza ainda que, aparentemente, através de seu desdém.

Para analisar certos ritos vigentes entre a elite do norte italiano do século XVII Burke refaz esse itinerário sociológico, concentrando sua atenção sobre a "obrigação de viver com fasto" (a ostentação como signo maior da riqueza), o "controle da impressão" (fazer-se retratar nas pinturas em certas atitudes compostas e cercado de alguns objetos associados à dignidade ou animais empregados na caça, como falcões, cavalos e cães), e também aquilo então denominado "quem fala que língua a quem e quando" (não apenas uma teoria do discurso como, notadamente, o emprego de astúcia na seleção do modo ${ }^{8}$ WINNICOTT, D.W. O brincar \& a realidade. Rio de Janeiro. Imago: 1975, p. 14. ${ }^{9}$ GOFFMAN, Erving. A representação do eu na vida cotidiana. Rio de Janeiro. $13^{\mathrm{a}}$ ed.Vozes: 2005, p. 221.

${ }^{10}$ BURKE, Peter. O mundo como teatro, ensaios de antropologia histórica. Lisboa. Difel: 1992. 
de falar, entre os vários disponíveis, manejando qual o mais adequado a tal ou qual situação).

“Tomar de empréstimo conceitos também é útil, mas mais perigoso. É preciso saber modificá-los, quando necessário, porque podem adaptar-se às diferentes situações. No entanto, sem tais conceitos teria sido impossível superar certos problemas do passado", adverte Peter Burke ao resumir as correlações possíveis entre a sociologia e a história. ${ }^{11}$

É uma forma de dramatização social, portanto, que vamos encontrar na base da teatralidade praticada em todas as instâncias da vida socialmente organizada. Ela não foi, historicamente, um traço exclusivo das sociedades da Itália, podendo ser captada em outras latitudes, como fez José Antonio Maravall ao discorrer sobre as sociedades barrocas da Espanha, nelas surpreendendo certas singularidades que, típicas do século XVII, correspondiam a perfis estruturais daquele contexto, como o adensamento populacional e a urbanidade, os contrastes sociais entre classes, o dirigismo empregado na política, na religião e na arte, a função da "conveniência" como parâmetro regulador das relações inter-pessoais. Isso lhe permitiu concluir:

\begin{abstract}
Na cidade barroca levantam-se templos e palácios, organizam-se festas e mais festas e montam-se deslumbrantes fogos de artifício. Os arcos de triunfo, os catafalcos para as homenagens fúnebres, os cortejos espetaculares - onde se vêem, senão nas grandes cidades? Nela existem Academias, se celebram certames, circulam folhas volantes, pasquins, libelos, escritos contra o Poder, ou por ele inspirados. Nela se constroem - grande novidade do tempo - lugares para teatro, e a população acorre a representações cênicas que têm em si a mais enérgica ação definidora da Cultura barroca. Nesses termos, a criação moderna do Teatro barroco, obra urbana pelo seu público, fins, recursos, é o instrumento por excelência da cultura da cidade. ${ }^{12}$
\end{abstract}

A percepção do estatuto dramático, bem como seus desdobramentos espetaculares - engrandecidos e adubados pela alta complexidade do século XX - em ação no conjunto das sociedades pós-industriais, mas agora enfatizado pelos efeitos do capital e pelas conseqüências abertas no rumo desenfreado do consumo de mercadorias, permitiu a Guy Debórd evocá-las sob a chancela de sociedade do espetáculo. Assoberbadas por desmesurada quantidade de imagens trespassando-as, as sociedades pós-modernas tendem a se calcarem inteiramente sobre a aparência, tornando o real um pseudomundo à parte, objeto de mera contemplação. "O espetáculo em geral, como inversão concreta da vida, é o movimento autônomo do não-vivo" ou "o espetáculo é o capital em tal grau de acumulação que se torna imagem", sustenta Debórd. ${ }^{13}$ Afetando simultaneamente as noções de tempo, de espaço, desfazendo a distinção entre o público e o privado, assenhoreando-se das ideologias para torná-las difusas e configuradas em novas imagens que retroalimentam o sistema,

a unidade irreal que o espetáculo proclama é a máscara da divisão de classes sobre a qual repousa a unidade real do modo de produção capitalista. O que obriga os produtores a participarem da construção do mundo é também o que os afasta dela. O que põe em contato os homens liberados de suas limitações locais e nacionais é também o que os separa. $\mathrm{O}$ que obriga ao aprofundamento do racional é também o que alimenta o irracional da exposição hierárquica e da repressão. $\mathrm{O}$ que constitui o poder abstrato da sociedade constitui sua não-liberdade concreta. ${ }^{14}$

\footnotetext{
${ }^{11}$ Idem, ibidem, p. 157.

${ }^{12}$ MARAVALL, José Antonio. A cultura do barroco. Lisboa. Instituto Superior de Novas Profissões: 1997, p. 176.

${ }^{13}$ DEBORD, Guy. A sociedade do espetáculo. Rio de Janeiro. Contraponto: 1997, p. 25.

${ }^{14}$ Idem, ibidem, p. 41.
} 
É nesse sentido que a teatralidade - destacada até este momento através de suas características enquanto jogo psicológico e alguns exemplos históricos - veio sulcando o desenvolvimento do ser humano e das sociedades em modo fértil, capaz de engendrar múltiplos e divisões de si mesma, compondo uma dimensão da vida social, a representação mesma da estrutura social. O teatral parece guardar, nesta perspectiva, um estatuto genético e funcional de procedência, decorrência do próprio dinamismo da cultura, onde o mimetismo, o jogo e a representação constituem impulsos que encontram nas práticas sociais canais de manifestação. Ele é tomado, portanto, como um núcleo organizado de mecanismos de produção de efeitos simbólicos, facetas que a corporificação adquire no tempo e espaço das sociedades históricas. Adquirindo o formato de uma metonímia (a parte pelo todo) ou a prevalência adjetiva sobre a substantiva, a teatralidade é tangível enquanto cumulação do que é teatral. 